\title{
Why should I trust ICT? An empirical study examining teachers and students usage of ICT for knowledge sharing and seeking
}

\author{
Kausar Fiaz Khawaja \\ Assistant Professor \\ Faculty of Management Sciences \\ International Islamic University, Islamabad Pakistan \\ kausar.khawaja@iiu.edu.pk
}

\begin{abstract}
The purpose of conducting this study is to examine factors affecting teachers and students trust on ICT and ICT usage behavior for knowledge sharing and seeking. Two empirical studies were conducted; and data was collected from teachers and students of two public sector universities that specifically offer distance learning programs and use ICT for knowledge sharing and knowledge seeking. For study-1, data was collected from 350 students,; whereas for study-2, data was collected from 150 teachers. Statistical tests for descriptive analysis, correlation analysis, confirmatory factor analysis, reliability analysis and mediation analysis were conducted. The mediation results suggested that trust mediates the relationship between facilitating condition (FC) and usage Behavior (UB) for both the studies as proposed. Moreover, trust and intention sequentially mediated the relationship between performance expectancy (PE), effort expectancy (EE), social influence (SI) and UB in both the studies except between EE, SI and UB of study-2.
\end{abstract}

Keyword: Knowledge sharing, knowledge seeking, Trust, ICT, UTAUT

http://dx.doi.org/10.30585/icabml-cp.v1i1.36

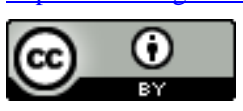

OPEN $\odot$ ACCESS

2523-6547 - Copyright: (C) 2017 The Authors. This is an open access article distributed under the terms of the Creative Commons Attribution License, which permits unrestricted use, distribution, and reproduction in any medium, provided the original author and source are credited. 


\section{Introduction}

The use of "web-based technologies" has expanded the quantity, quality and density of knowledge; and encouraged the proliferation of "virtual teaching/learning environment". Such technologies provides platform for geographically dispersed instructors and learners; so that they could accomplish their goal of knowledge sharing and seeking. But despite the proliferation of "virtual teaching/learning environment", still in depth study on user technology acceptance behavior for knowledge exchange (KE) has received limited concentration over the past years. Similar observation was made by Sumak, Hericko and Pusnik (2011); that no doubt technology acceptance model (TAM) has been extensively used for examining e-learning acceptance; but "limited studies have used unified theory of acceptance and use of technology (UTAUT) as a ground theory; therefore future research needs to include studies that will evaluate this state-of-art theory in the field of e-learning acceptance”.

Now, the question arises, that if TAM has been extensively used, than why there is a need to have UTAUT as a base theory. Basically, UTAUT was developed by Venkatesh, Morris, Davis and Davis (2003), based on the observation that researchers in past conduct studies by selecting any one developed model; thus leaving a doubt of ignoring some important variables that must be tested to evaluate user technology acceptance behavior. Henceforth, to overcome this issue, Venkatesh and his colleagues aligned together all related variables and proposed four key names: "performance expectancy", "effort expectancy", "social influence", and "facilitating condition". Although TAM has been widely used for testing user e-learning acceptance; "but it has been criticized for not giving consistent and conclusive results" (Mac-Callum \& Jaffrey, 2013). Therefore, unified theory with the help of unified factors may present a broader view about factors affecting user intention.

To proceed with the current study, all past researches that considered UTAUT was reviewed. Moreover keeping in view the suggestions presented by Sumak et al.,(2011) and Venkatesh, Thong and Xu (2012) that to include other factors that could extend the UTAUT; trust has been observed as an important element in making "exchange relationship" successful. In addition an "apparent dearth of literature on investigating trust in the context of elearning or understanding its antecedents or determinants thoroughly" was also reported (Wang, 2014). Similar gap was identified after reviewing meta-analyses on UTAUT, that till date no study has investigated user trust on e-learning system (Williams, Rana, \& Dwivedi, 2012).

Along with the existence of theoretical gap identified above, review of literature also revealed that KE phenomena itself had not been extensively studied and so is misinterpreted: Firstly, the success of KE is not only based on sharing but also on how well the knowledge is received (Kankanhalli et al., 2005). Past literature revealed extensive research on users knowledge sharing behavior, but limited studies investigated knowledge seeking behavior (i.e. Kankanhalli et al., 2005; Gray \& Durcikova, 2005; Bock, Kankanhalli \& Sharma, 2006; Watson \& Hewett, 2006; Lin \& Huang, 2008; He, Fang \& Wei, 2009; He and Wei, 2009; Phang, Kankanhalli \& Sabherwal, 2009; Chen and Hung, 2010; Kankanhalli, Lee \& Lim, 2011). Similar future direction was illustrated by Lai, Chen and Chang (2014) that a "thorough comprehension of knowledge seeking behavior by developing an integrative model in virtual communities" is needed.

Secondly, in past studies, same respondents responded for their knowledge sharing and knowledge seeking behavior; hence leaving a doubt that they might have failed to "distinguish their contribution and seeking perceptions when answering these two questions at a time" (He and Wei, 2009). Moreover, Ghadirian, et al., (2014) after reviewing literature on knowledge exchange in learning communities reported that "limited attentions have been dedicated towards users knowledge sharing and seeking behavior in online learning environment". Thus, researchers directed that in future "knowledge exchange should be examined from different theoretical perspective by investigating the potential mechanism through which knowledge sharing and seeking in virtual environment can be fostered".

2523-6547 - Copyright: (C) 2017 The Authors. This is an open access article distributed under the terms of the Creative Commons Attribution License, which permits unrestricted use, distribution, and reproduction in any medium, provided the original author and source are credited. 
Hence on the basis of the above mentioned literature, identified with respect to KE phenomena and UTAUT, this research is of high "theoretical significance". Firstly this study examines teachers and students intention to use ICT for knowledge sharing and seeking separately. Secondly, based on the research gap reported above; the current study reported trust as an important element; that mediates the relationship between UTAUT constructs and user intention to use ICT for knowledge exchange (as shown in figure 1).

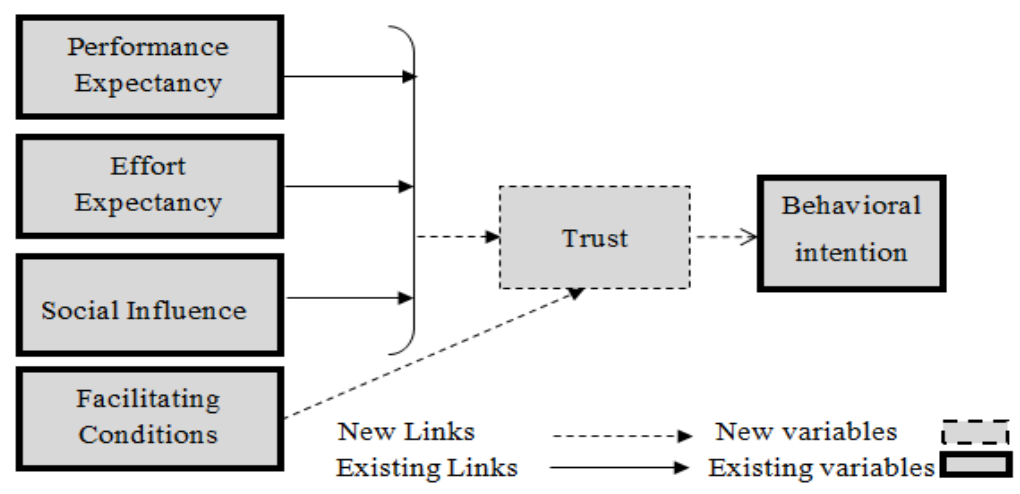

Figure 1: Extended UTAUT model

\section{Literature Review}

\section{Performance Expectancy (PE) relationship with trust}

Performance Expectancy (PE) is one of the constructs of UTAUT and defined as "the degree to which an individual believes that using the system will help the user to attain gains in job performance" (Venkatesh et al., 2003), and according to this study its knowledge sharing and seeking.

Trust is considered as an important element that reduces users perception related to uncertainty and risk associated with the technology. As online learning is a new form of educating individuals, high uncertainty and risk exist. This may be because previously, the teachers and students have been associated to traditional teaching/learning methods; therefore online teaching/learning is less known to students and teachers. Moreover, as student and teacher cannot physically communicate with each other; therefore it is believed that ICT makes it difficult for them to deliver and understand the lecture. Wang (2014) reported that for teachers and students it's not an easy decision to opt for virtual learning; as fear w.r.t wastage of money, time, unavailability of Internet and failure to deliver or explain lecture due to the absence of face-to-face interaction exist. Hence to make ICT trustworthy for teachers and students, it is important that ICT fulfills the goal or objective which it is designed for. Similar to this, Suh and Han (2002) conducted a study on Internet banking and reported perceived usefulness as one of the essential factors that influenced user trust. Their study revealed that "Internet banking is of great benefit to customers" as it saves time and cost, with zero location dependence, quick feedback and with more updated services. These features associated with Internet banking, increased the performance of banking activities; which eventually influenced customer trust.

In general, trust is based on four essential beliefs ("competence belief", "fulfillment belief", "dispositional belief”, "dependence belief") that explain that customers trust a technology only if they believe: (a) it will accomplish the required output/goal, (b) it is the best option to rely on for fulfilling the requirements and (c) the system is actually willing to complete the task assigned to it (Castelfranchi \& Falcone, 1998 cited in Tan \& Thoen, 2000). For example: system operator trusts an automated system is dependent on its "perceived technological competence, performance" and its usefulness (Lee \& Moray, 1992). Similar suggestion was proposed by Kini and Choobineh (1998) explaining that trust on e-vendor for an online shopping is very important. And for a user to make an online transaction, he/she must trust a technology which is based on the competence and performance of the technology in use. Hence, on the bases of these arguments the current study proposes that "performance expectancy" influences user trust on ICT.

2523-6547 - Copyright: (C) 2017 The Authors. This is an open access article distributed under the terms of the Creative Commons Attribution License, which permits unrestricted use, distribution, and reproduction in any medium, provided the original author and source are credited. 
Hypothesis 1a: Performance expectancy has a positive influence on user (student) trust on ICT for knowledge seeking.

Hypothesis $1 b$ : Performance expectancy has a positive influence on user (teacher) trust on ICT for knowledge sharing.

\section{Effort Expectancy (EE) relationship with Trust}

"Effort expectancy" (EE) is the second most important construct of UTAUT and is defined as "the degree of ease associated with the use of system".

To make a user feel that the system is trustworthy; it is important to treat weak and untrained individuals, positively and impartially (Hart \& Saunders, 1997; Kumar 1996). In a normal business environment where a person gets in contact with a vendor, it "subconsciously" looks for cues from his behavior and appearance inorder to decide whether to trust him or not (Blau, 1964). But in e-commerce sites where the user communicates through the technology, it is important for the site to be effortless and less complex. These elements eventually help in building user trust (Gefen et al., 2003). Similar findings were revealed by Chinomona (2013) while examining user acceptance for "mobile social software". The study reported a significant influence of EE on trust; revealing that when users perceive "mobile software" effortless, there are more likely chances of trusting that software.

It is believed that perceived ease associated with the use of information communication technology (ICT) is essential for "information gathering", as it enhances the efficiency of a customer using the system. Therefore, when teachers and students use ICT for KE, they consider it trustworthy, if they find it less complex, accessible, with up-to-date information, ease in uploading, downloading and searching. Hence based on the past empirical evidence (Corritore et al., 2003; Gefen et al., 2003) current study investigates the impact of effort expectancy on trust and so hypothesis 2 is proposed.

Hypothesis 2a: Effort expectancy has a positive influence on user (student) trust on ICT for knowledge seeking. Hypothesis 2b: Effort expectancy has a positive influence on user (teacher) trust on ICT for knowledge sharing.

\section{Social Influence (SI) relationship with trust}

Social Influence is the person's perception that most people who are important to him, think that he should or should not perform behavior (Karahanna, Straub \& Chervany, 1999, Fishbein \& Ajzen, 1975). Similarly Venkatesh et al., (2003) defined social influence as "the degree to which an individual perceives that some important others believe he should or should not use the new system".

It is believe that individual trust an object on the basis of the preferences or recommendations from familiar people (friend, family, peers/colleagues, and celebrities), but studies also reported trust among dissimilar groups in traditional working environment (Williams, 2001). Although distrust among dissimilar groups were assumed and some evidence suggested the same (For e.g. Cox, 1994; Kelly \& Kelly, 1991); but there are studies that reported a significant level of trust among dissimilar professionals (McKnight, Cummings \& Chervancy, 1998; Meyerson, Weick \& Kramer, 1996). This trust among dissimilar groups is due to the positive beliefs and positive influence about the competencies of others (Meyerson et al., 1996) as in the case of famous celebrities or people in society etc.

In 1958, Kelman proposed a social influence theory explaining 3 varieties of "Social Influence". "Social Identification" is one of those that gained major appreciations by the theorists. "Social Identification" was defined as "when people are influenced by someone who is liked and respected, such as famous celebrity" (Social Influence, 2015) or "when people adopt behavior to achieve a satisfying and self-defining relationship with another person or group" (Kelman, 1958). Hence illustrating that "effective", "collaborative", and "cohesive" working environment within an organization (Hopgood \& Hirst, 2007) leads to trust, loyalty and productivity (Ho, Kuo and Lin, 2012), whereas negative subjective norm leads to distrust of an individual towards an object. For example: Azizi (2014) in a study reported the effect of negative subjective norm on consumer trust. The research was conducted in Iran on Korean products and found that due to negative: (a) words of mouth, (b) social norms, and (c) beliefs upon foreign products; the level of trust reduced.

2523-6547 - Copyright: (C) 2017 The Authors. This is an open access article distributed under the terms of the Creative Commons Attribution License, which permits unrestricted use, distribution, and reproduction in any medium, provided the original author and source are credited. 
In most of the empirical studies conducted on e-commerce; researchers examined trust using constructs of technology acceptance model (TAM) and theory of planned behavior (TPB). Among them, only perceived usefulness (PU) and perceived ease of use (PEOU) remained the centre of interest for researchers. Hence the relationship between social influence and trust has hardly been studied, although researchers have referred the role of referent groups in defining user's online trust. For example, in holistic framework of trust, Li et al., (2012) described laws and regulations, trusted known entity as an antecedent of online trust. Hence third parties who influence individuals to share knowledge can be individuals or organizations whose interests are meant something to others.

However up to author's knowledge, no such research has been conducted where explicitly the relationship between SI and trust on any technology artifacts were studied. Therefore, the current study, in the light of literature presented above, suggests a positive and significant relationship between social influence and trust; and so hypothesis 3 is proposed.

Hypothesis 3a: Social influence has a positive influence on user (student) trust on ICT for knowledge seeking. Hypothesis 3b: Social influence has a positive influence on user (teacher) trust on ICT for knowledge sharing.

\section{Facilitating Condition (FC) relationship with trust}

Facilitating condition (FC) is defined as "the degree to which an individual believes that an organizational and technical infrastructure exists to support use of the system" (Venkatesh et al., 2003) i.e. user ICT usage behavior is based on the support an individual gets from organization environment.

Trust on an e-vendor or on a technology explains that it will achieve the required outcome. And in order to achieve the required result individuals believe that the objective conditions should be available (McKnight \& Chervany, 2002). These conditions are in the form of "IT connectivity", "Standards", "guidance" and "in-time feedback" (Pavlou, Tan \& Gefen, 2003). McKnight et al., (2002) investigated a significant influence of "structural assurance" (SA) on trust, reporting that because of SA user may overcome his fear related to use of Internet and will be comfortable using it. Similarly, Lu et al., (2005) conducted a study on "wireless mobile technology" and found that the guidance and support to use a technology helps in building trustworthy environment, whereas the unavailability of live human support in an e-marketplace is the cause of making business environment questionable (Karimov, Brengman, Van-Hove \& Van, 2011). In addition, past research also reported language barrier, outdated technology, and unstable power supply (Oye, Salleh, \& Iahad, 2011) as a challenge for knowledge exchange in an organization, which eventually affects users trust towards technology (Wang \& Noe, 2010). In order to overcome these issues and to provide support to the users, images and video clips are uploaded on the website for the guidance (Karimov et al., 2011). Actually it helps in building user belief and trust on the technology, which further influences user intention. Along with the "social media application" guidance in the form of live help chat (Qiu \& Benbasat, 2005) and use of intelligent software agents also result in building user trust on technology.

Therefore based on the above mentioned references from the literature; the current study proposes a significant relationship between FC and trust. Hence, hypothesis 4 is proposed.

Hypothesis 4a: Facilitating conditions has a positive influence on user (student) trust on ICT for knowledge seeking.

Hypothesis 4b: Facilitating conditions has a positive influence on user (teacher) trust on ICT for knowledge sharing.

\section{Trust and Intention}

Trust is considered as an important element in defining situations where uncertainty exist (Ba \& Pavlou, 2002). It has been observed as a key factor that explains most of the successful transactions (Pavlou, 2003) (like ecommerce, virtual teams) by influencing "user intention" (Jarvenpaa, Tractinsky \& Saarinen, 1999; Gefen \& Straub, 2003; Gefen et al., 2003). For example in online shopping it is believed that "Trust based relationships" helps in reducing consumers concerns related to uncertainty, ambiguity and risk for an e-vendor or an online shopping website (Wang and Benbasat, 2005); and therefore stimulate users positive intention towards the

2523-6547 - Copyright: (C) 2017 The Authors. This is an open access article distributed under the terms of the Creative Commons Attribution License, which permits unrestricted use, distribution, and reproduction in any medium, provided the original author and source are credited. 
purchase (Jarvenpaa et al., 1999). Hence, if users (online shoppers) distrust an e-vendor or a technology, it will stop users to shop online (Reichheld \& Schefter, 2000). Similarly trust on communicating technologies is considered important when forming virtual teams (Jarvenpaa, Shaw \& Staples, 2004). This is because prior to Internet the only mean through which team members communicate were face to face meetings, but as technology has changed the conditions of communication (w.r.t physical infrastructure, division of task etc.) therefore members might perceive uncertainty and ambiguity when communicating online; as a result they resist using technology. Hence, team members' trust on communication technologies is important as it helps in building their intention (Grabner-Krauter \& Kaluscha, 2003).

Keeping in view the current study, similar trust on ICT is needed in order to build user positive intention towards using ICT for knowledge exchange. In general, teacher and student has been associated with the traditional teaching and learning method; and educational institutes in order to achieve their man objective arrange face to face lecture sessions; where, with the help of verbal and non-verbal communication, teachers and students clear their concepts and ask questions etc. But with the evolution of ICT in educational sector, change in the conditions of knowledge sharing and seeking has been observed. In such a situation users concerns related to perceived ambiguity, uncertainty and risk towards the use of ICT may arise, that negatively influences user intention to use ICT. Therefore, it is important to know whether teachers and students find ICT reliable, helpful in sharing and seeking knowledge, that eventually increases their behavioral intention or not. Hence, based on the assertion laid by the past researchers; in the current study trust on ICT is proposed as a determinant of user intention; and so hypothesis 5 is proposed.

Hypothesis 5a: User (student) trust on ICT has a positive influence on behavioral intention to use ICT for knowledge seeking.

Hypothesis 5b: User (teacher) trust on ICT has a positive influence on behavioral intention to use ICT for knowledge sharing.

\section{Methodology}

\section{Data collection}

Two cross-sectional studies were conducted to assess factors determining user trust on ICT that further influence user intention to use ICT for knowledge sharing and seeking. The sampling consists of male and female students and teachers of two public sector universities that solely offer distance learning programs. Hence purposive quota sampling technique was used.

The process for data collection comprised of almost two academic semesters. The respondents during the start of the semester were requested to respond for questionnaire. Total 500 (350 students and 150 teachers) respondents who used ICT for knowledge exchange, opted to participate in the study. Almost 130 responses were rejected; where respondents either (a) failed to fill the complete questionnaire; or (b) responded twice. Only the researcher of the current study had the access to view the data sheet, as the confidentiality of respondents view was maintained.

Study 1: For study 1, subjects selected for conducting study were students, who use ICT for knowledge seeking. Respondents were asked to fill questionnaire containing items on independent variables (IV) and dependent variable (DV). In total, 435 respondents responded. After deleting incomplete and duplicate cases; in total 350 students successfully participated and filled the complete questionnaire.

Study 2: For study 2, subjects selected for conducting research were teachers, who use ICT for knowledge sharing. For this, permanent and visiting faculty members of two public sector universities were requested. Similar to study 1 , teachers were requested to respond with same items. 163 responses were received. After the scrutiny, in total 150 usable responses were selected for data analysis.

\section{Measures:}

It is believed that the most suitable tool use for conducting research is questionnaire. And it is comprised of items related to different constructs that has to be measured (Sekaran, 2003). There are four steps involved in developing

2523-6547 - Copyright: (C) 2017 The Authors. This is an open access article distributed under the terms of the Creative Commons Attribution License, which permits unrestricted use, distribution, and reproduction in any medium, provided the original author and source are credited. 
and using the questionnaire for analysis. First: to outline the constructs of the study and their content. Second: to test the content-face validity of the scale. Third: performing the validity and reliability test. Fourth: analyzing the data using different statistical technique as per scope of the research (Sekaran, 2003). However, the current section (research methodology) deals with first two steps only; whereas use of statistical techniques and its analysis (step 3 and 4) has been reported in results and discussion section.

To develop a questionnaire for the current research, literature and gap of the study with respect to the usage of information systems (i.e. ICT used for distance education) were reviewed and constructs were finalized. Literature on the selected constructs helped in analyzing and adapting the scale items. Adapting an instrument is needed when "an instrument is not appropriate for the unique participants in the study" and substantial changes are needed according to the requirement of the study like adding, removing or changing the content of items (Korb, 2012). For the current research, previously developed and tested instruments of Venkatesh et al., (2003); Taylor and Todd (1995) Davis et al., (1989) and Cho and Fiorito, (2009) were adapted, keeping in mind the ICT for knowledge exchange. As, Hair et al., (2010) reported that "face validity of the instrument solely based on researchers judgment", therefore, items of each construct were slightly adapted by replacing system/website with ICT and adding terms assignment, lecture, teaching/learning and knowledge sharing/seeking as per requirement. Hence, scales were adapted from past researches. Like: items of performance expectancy, effort expectancy, social influence, and facilitating conditions were adapted from Venkatesh et al., (2003). Items for behavioral intention were adapted from Taylor and Todd (1995). Trust was measured using scale adapted from Cho and Fiorito, (2009). Lastly, all the items were measured using seven point-likert scales ranging from strongly disagree to strongly agree.

For analyzing the data, SPSS 19 and AMOS 16 were used. Statistical techniques like: confirmatory factor analysis, cronbach alpha, descriptive analysis, correlation and structural equation modeling (SEM) were run.

\section{Results and Discussions}

The analysis of study 1 and study 2 begins with data screening followed with measurement model testing. Statistical techniques like: average variance extracted (AVE), confirmatory factor analysis (CFA), reliability, descriptive analysis, and regression analysis were conducted to evaluate the gathered data.

\section{Data Screening}

To begin with data analysis, data was screened in order to examine dataset for errors. Hair, Black, Babin and Anderson, (2010); and Meyers et al., (2012) suggested the following three procedures of data screening: (a) Missing data analysis; (b) Outlier detection (c) Normality test (Skewness and Kurtosis).

Missing data analysis is conducted to assure whether respondents responded for all the required variables or not. Keeping in view the current research, all incomplete and duplicate responses were eliminated from both the studies. Hence, for study 1, total 350 responses were selected for data analysis; whereas for study 2; total of 150 responses were selected for analysis.

Hair et al., (2010) defined outliers as "observations with a unique combination of characteristics identifiable as distinctly different from the other observations". To statistically examine the outliers; "standard scores i.e. Zscores" for each item has to be calculated. For sample size that are more than 80 , the "threshold value of standard scores is up to \pm 4 " (Hair et al., 2010). Hence, the cases depicting standard scores greater than \pm 4 are considered as outliers. Using this criterion, in the current research (for study 1 and study 2), standard scores for each item was calculated. Fortunately, all scores depicted values within the given range.

Lastly, after removing the missing data and the outliers from the dataset, normality of the data is examined i.e. to check whether data is normally distributed or not. And to statistically examine the univariate normality of data; two tests skewness and kurtosis were performed. The recommended Z-skewness value ranges from -3 to +3 , whereas, the recommended Z-kurtosis value ranges from -7 to +7 (Coakes \& Steed, 2003). However, review of past literature and suggestions proposed by the statisticians revealed that, "majority of data collected in behavioral research do not follow the univariate normal distribution" (Curran, West \& Finch, 1996). This conclusion is based

2523-6547 - Copyright: (C) 2017 The Authors. This is an open access article distributed under the terms of the Creative Commons Attribution License, which permits unrestricted use, distribution, and reproduction in any medium, provided the original author and source are credited. 
on the assumption that in ordinal scale, respondent has to select from the given range (like: likert scale of 1 to 5 or 1 to 7) therefore, normality of data cannot be an issue.

After performing the tests for normality, the results of this research depicted non-normal data. However, rejecting the assumption of normality has no direct effect over the analysis of exogenous and endogenous relationship. This is because, Norman (2010) when investigated about the non-normality of likert scale (ordinal scale) and the use of parametric test; reported that parametric statistics (tests for normally distributed data) "can be used with likert data, with small sizes, with unequal variance and with non-normal distribution, with no fear of coming to the wrong conclusion". These findings were based on the "empirical literature" reported in the last eighty years.

Researchers referred bootstrapping method inorder to overcome the issue of non-normal data. It involves "estimating a model many times using simulated data" (Mackinnon, 2006) i.e. "resampling with replacement of data which is done many times e.g. 5000 times" (Kenny, 2014). Hence, keeping in view the need of the research, bootstrapping method was used. For this SEM was conducted using statistical software AMOS.

\section{Measurement Model Evaluation}

Before analyzing the relationship between exogenous and endogenous variables, researchers recommended to perform measurement model testing (Byrne, 2010; Kline, 2011). To evaluate the measurement model and its adequacy; CFA is conducted. On a broader view, measurement model testing comprises of following procedures: (a) specification, (b) estimation, (c) evaluation of fit, (d) interpretation and reporting, (e) re-specification (Hoyle, 2012). In case, after first four steps the measurement model is depicted free from errors, the researcher then proceeds with hypotheses testing. But, if the measurement model requires modification; then researcher has to respecify - re-estimate - re-evaluate the goodness of fit and reliability-validity tests. This process goes on until the measurement model is fit for further procedures.

Initial measurement model analysis: To begin with the measurement model testing, initial CFA was conducted on twenty three indicators of six latent variables. With reference to non-normality of data, maximum likelihood estimation technique was used for conducting CFA (Ullman, 2006; Kline, 2011). The generated output file using AMOS, illustrates the results of factor loadings, modification indices and fit indices. Estimation of factor loadings, fit indices and modification indices for initial measurement model are:

CFA illustrates factor loadings of each item; that actually verifies the association between factor indicators and the latent variable. Fortunately, all the factor loadings of initial measurement model for study 1 and study 2 depicted values above 0.40; as suggested by Tabachnick and Fidell (2007) and Stevens (2002). To begin with the estimation of model fit; normal chi-square (CMIN/DF) along with other fit indices values were calculated (Ullman, 2006). Comparative fit index (CFI), incremental fit index (IFI), TLI, goodness of fit index (GFI) values should be greater than 0.90 . However, values' ranging from 0.80 to 0.89 is considered as "marginal fit. Similarly, for "root mean square error of approximation" (RMSEA) the value less than 0.05 is considered as "good"; value ranging from 0.05 to 0.08 as "reasonable fit" (Byrne, 2010).

Unfortunately, the values depicted unacceptable model fit (as shown in table 1); as a result modification indices (MIs) were viewed to re-specify the measurement model. The MIs illustrates covariance between error terms of indicators; that eventually helps in identifying the problematic indicator. After specification search and evaluation of the initial measurement model; three indicators/items (PE2, SI4, T3) were found misfit. Decision was made because: (a) strong covariance was reported between the error terms of PE2, SI4, T3 and error terms of other indicators; that may cause discriminant validity issue (Hair et al., 2010) (b) indicators did not explain the area of interest.

Final (re-specified) measurement model analysis: Hoyle (2012) reported that for re-specified measurement model; re-estimation - re-evaluation of model fitness and analysis of validity - reliability tests are needed. Hence, based on these assumptions, the re-specified final model was re-estimated and re-evaluated for model fitness using 20 indicators of six latent variables. For study 1 and study 2, the output file depicts an improved chi-square and CMIN/DF value; with fit indices (GFI, CFI, TLI, and IFI) within acceptable range; factor loadings greater than 0.40 and a decrease in RMSEA value; as suggested in the literature. Moreover study confirms the convergent validity; discriminant validity and composite reliability (see table1 and table 2)

2523-6547 - Copyright: (C) 2017 The Authors. This is an open access article distributed under the terms of the Creative Commons Attribution License, which permits unrestricted use, distribution, and reproduction in any medium, provided the original author and source are credited. 
Table 1: Comparison between the results of initial and final (re-specified) measurement model

\begin{tabular}{|c|c|c|c|c|c|}
\hline \multirow{2}{*}{ Fit Indexes } & $\begin{array}{c}\text { Results of } \\
\text { initial } \\
\text { Measurement } \\
\text { Model } \\
\text { (i.e. Model 1) }\end{array}$ & $\begin{array}{c}\text { Results of final } \\
\text { (re-specified) } \\
\text { Measurement } \\
\text { Model } \\
\text { (i.e. Model 2) }\end{array}$ & $\begin{array}{c}\text { Results of } \\
\text { initial } \\
\text { Measurement } \\
\text { Model } \\
\text { (i.e Model 1) }\end{array}$ & $\begin{array}{c}\text { Results of final } \\
\text { (re-specified) } \\
\text { Measurement } \\
\text { Model } \\
\text { (i.e Model 2) }\end{array}$ & Improvement \\
\hline Chi-square & 800.652 & 385.32 & 495.625 & 234.79 & Improved \\
\hline CMIN / DF & 3.724 & 2.752 & 2.305 & 1.677 & Improved \\
\hline GFI & 0.838 & 0.902 & 0.781 & 0.867 & Improved \\
\hline AGFI & 0.792 & 0.853 & 0.719 & 0.800 & Improved \\
\hline CFI & 0.857 & 0.930 & 0.839 & 0.934 & Improved \\
\hline TLI & 0.832 & 0.905 & 0.811 & 0.910 & Improved \\
\hline IFI & 0.858 & 0.931 & 0.843 & 0.936 & Improved \\
\hline RMSEA & 0.088 & 0.071 & 0.094 & 0.067 & Improved \\
\hline
\end{tabular}

Table 2: Validity and Reliability analysis

\begin{tabular}{|c|c|c|c|c|c|c|c|c|}
\hline & \multicolumn{4}{|c|}{ Study 1} & \multicolumn{4}{|c|}{ Study 2} \\
\hline & $\begin{array}{c}\text { Convergent } \\
\text { Validity } \\
\end{array}$ & DV & $\begin{array}{c}\text { Internal } \\
\text { Reliability }\end{array}$ & \multirow{2}{*}{ CR } & $\begin{array}{c}\text { Convergent } \\
\text { Validity } \\
\end{array}$ & DV & $\begin{array}{c}\text { Internal } \\
\text { Reliability } \\
\end{array}$ & \multirow{2}{*}{ CR } \\
\hline & AVE & $\begin{array}{l}\text { Sqrt } \\
\text { AVE }\end{array}$ & $\begin{array}{c}\text { Cronbach } \\
\text { Alpha }\end{array}$ & & AVE & $\begin{array}{l}\text { Sqrt } \\
\text { AVE }\end{array}$ & $\begin{array}{c}\text { Cronbach } \\
\text { Alpha } \\
\end{array}$ & \\
\hline $\mathbf{P E}$ & 0.697 & 0.835 & 0.878 & 0.873 & 0.720 & 0.848 & 0.899 & 0.884 \\
\hline EE & 0.550 & 0.742 & 0.832 & 0.829 & 0.535 & 0.732 & 0.857 & 0.820 \\
\hline SI & 0.561 & 0.749 & 0.714 & 0.790 & 0.537 & 0.733 & 0.607 & 0.760 \\
\hline FC & 0.568 & 0.753 & 0.798 & 0.839 & 0.588 & 0.767 & 0.747 & 0.842 \\
\hline Trust & 0.611 & 0.782 & 0.782 & 0.825 & 0.517 & 0.719 & 0.708 & 0.763 \\
\hline INT & 0.540 & 0.735 & 0.795 & 0.777 & 0.582 & 0.763 & 0.819 & 0.806 \\
\hline
\end{tabular}

$\mathrm{PE}=$ Performance Expectancy $; \mathrm{EE}=$ Effort Expectancy; SI = Social Influence, $\mathrm{FC}=$ Facilitating Conditions, INT= Behavioral Intention, $\mathrm{CR}=$ Composite Reliability; DV = Discriminant Validity 


\section{Descriptive Statistics, Correlation}

Prior conducting statistical tests for proposed hypotheses, a descriptive analysis and correlation analysis were conducted. Table 3; 4a \& 4b illustrates variables mean, standard deviation (SD) respectively, along with positive association between the variables.

Table 3: Descriptive statistics

\begin{tabular}{|c|c|c|c|c|c|c|c|c|}
\hline \multirow{2}{*}{ Construct } & \multicolumn{4}{|c|}{ Study 1} & \multicolumn{4}{|c|}{ Study 2} \\
\hline & Mean & SD & Frequency & \%age & Mean & SD & Frequency & \%age \\
\hline Male & \multirow{2}{*}{1.42} & \multirow{2}{*}{0.49} & 203 & 58.00 & \multirow{2}{*}{1.35} & \multirow{2}{*}{0.48} & 97 & 64.70 \\
\hline Female & & & 147 & 42.00 & & & 53 & 35.30 \\
\hline$<20$ & \multirow{5}{*}{2.23} & \multirow{5}{*}{0.57} & 19 & 5.40 & \multirow{5}{*}{3.47} & \multirow{5}{*}{0.75} & 0 & 0 \\
\hline $20-30$ & & & 237 & 67.70 & & & 13 & 8.70 \\
\hline $31-40$ & & & 87 & 24.90 & & & 64 & 42.70 \\
\hline 41-50 & & & 7 & 2 & & & 62 & 41.30 \\
\hline $51 \&$ above & & & 0 & 0 & & & 11 & 7.30 \\
\hline
\end{tabular}


Table 4a: Mean, SD, Correlation Analysis for Study 1

\begin{tabular}{|c|c|c|c|c|c|c|c|c|}
\hline Construct & Mean & SD & PE & EE & SI & FC & TRUST & INT \\
\hline PE & 5.06 & 1.46 & 1 & & & & & \\
\hline EE & 5.09 & 1.115 & $0.582^{* *}$ & 1 & & & & \\
\hline SI & 5.04 & 1.147 & $0.472^{* *}$ & $0.568^{* *}$ & 1 & & & \\
\hline FC & 4.87 & 1.076 & $0.419^{* *}$ & $0.498^{* *}$ & $0.379^{* *}$ & 1 & & \\
\hline Trust & 4.88 & 1.142 & $0.483^{* *}$ & $0.520^{* *}$ & $0.474^{* *}$ & $0.430^{* *}$ & 1 & \\
\hline INT & 4.96 & 1.255 & $0.564^{* *}$ & $0.563^{* *}$ & $0.462^{* *}$ & $0.364^{* *}$ & $0.564^{* *}$ & 1 \\
\hline
\end{tabular}

** Correlation is significant at the 0.01 level (2-tailed).

Table 4b: Mean, SD, Correlation Analysis for Study 2

\begin{tabular}{|c|c|c|c|c|c|c|c|c|}
\hline Construct & Mean & SD & PE & EE & SI & FC & TRUST & INT \\
\hline PE & 5.28 & 1.39 & 1 & & & & & \\
\hline EE & 5.14 & 1.13 & $0.575^{* *}$ & 1 & & & & \\
\hline SI & 4.96 & 1.13 & $0.486^{* *}$ & $0.516^{* *}$ & 1 & & & \\
\hline FC & 5.08 & 0.95 & $0.389^{* *}$ & $0.444^{* *}$ & $0.299^{* *}$ & 1 & & \\
\hline TRUST & 5.13 & 0.96 & $0.461^{* *}$ & $0.318^{* *}$ & $0.388^{* *}$ & $0.387^{* *}$ & 1 & 1 \\
\hline INT & 5.14 & 1.24 & $0.504^{* *}$ & $0.546^{* *}$ & $0.375^{* *}$ & $0.397^{* *}$ & $0.423^{* *}$ & 1 \\
\hline
\end{tabular}

** Correlation is significant at the 0.01 level (2-tailed).

Note: PE=Performance Expectancy, EE=Effort Expectancy, SI=Social Influence, FC=Facilitating Condition, INT= Behavioral Intention.

\section{Hypothesis testing:}

UTAUT constructs (performance expectancy, effort expectancy, social influence, and facilitating conditions) has a positive and significant influence on user trust on ICT for knowledge sharing and seeking.

The results revealed a significant and positive relationship between all UTAUT constructs and trust of study 1 and study 2, except for "effort expectancy" (EE) on "trust" of study 2, which resulted insignificantly. Following paragraphs explains each relationship in detail.

"Performance expectancy" (PE) has a positive and significant effect on trust. The result is consistent with the previous studies, where researchers investigated that user's trust a technology only if they believe that it will achieve the defined goals (for which it has been used) and will help in performing the task. Similar concept was discussed by Olson and Jacoby (1972) that consumers trust a product on the basis of benefits associated with its usage. Although it would not be possible to evaluate the intrinsic attributes of a product; but extrinsic attributes like: perceived quality and reliability of the product influences individuals trust (Brengman \& Karimov, 2012). Similarly, Suh and Han (2002) while explaining the benefits associated with the usage of Internet banking reported that 24/7 availability of banking service, with zero travelling cost and no time strain helps in building user trust on Internet banking.

In this study, the significant effect of PE on trust; revealed coefficient path values for study $1(0.155, \mathrm{p}<0.001)$ and study $2(0.216, \mathrm{p}<0.001)$ respectively. The result explains that students and teachers who use ICT for knowledge exchange consider it useful and belief it to be supportive in accomplishing their task of knowledge sharing and seeking. In addition, the findings also indicated that the coefficient path of study 2 is greater than study 1 . This might be because in virtual teaching environment, teachers impart their knowledge using ICT either by uploading the PowerPoint slides; using video conferencing for knowledge sharing. These knowledge sharing techniques are somehow similar to the traditional teaching methodology, where instructor enters the classroom, runs the PowerPoint slides and delivers the lecture.

But in contrary, students have to place efforts to understand lectures in the absence of instructor. In case of any ambiguity, instructor can be contacted via an email/message, and he might respond to the question when he reads it. In traditional learning environment, students can raise questions during the lectures and teachers address them with in the class. Therefore, the lower value of coefficient path in study 1 can be because of the above mentioned 
reasons. But overall teachers and students consider ICT useful for knowledge sharing and seeking, and therefore possess trust on ICT.

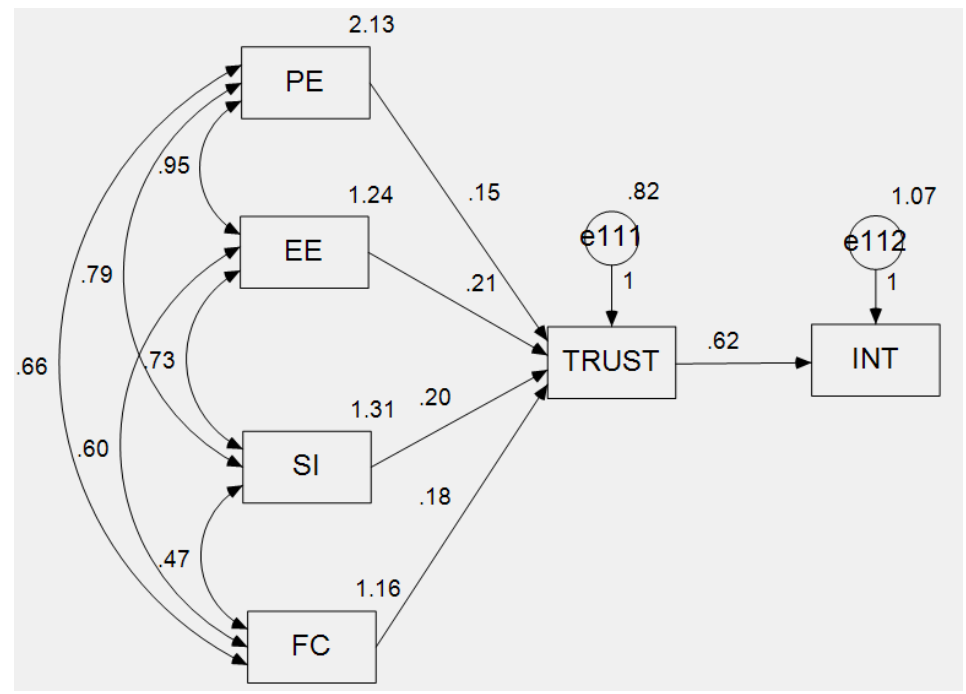

Figure 2: Structural Model - Extended UTAUT model for Study 1

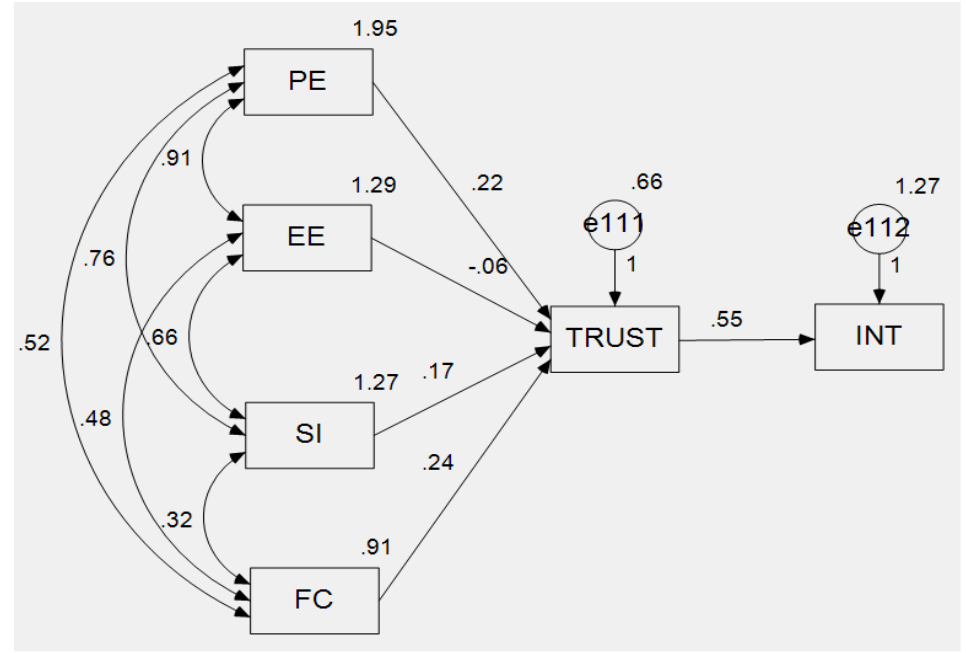

Figure 3: Structural Model - Extended UTAUT model for Study 2

The results revealed that "effort expectancy" (EE) has a significant effect on trust in study 1, whereas an insignificant effect on trust in study 2 . The difference in opinion might be because of the difference in their age group, who opted to participate in both the studies. Maximum students, who voluntarily participated in study 1 , were in 20s and 30s; whereas findings revealed that maximum teachers participated in study 2 were of age group $31-50$.

Researchers referred "Graduates and Undergraduates" as "DOTNET GENERATION", who rely on technology to perform their daily routine activities, Like: online job search, online interview, e-commerce, online auction, online admission, communication via emails or mobile phones, social networking etc. As they interact with different technologies daily, they consider them effortless and trustworthy. But on the other hand, demographic statistics of the teachers revealed that as most of them were in 30s and 40s, have been dealing with things manually in past and have themselves seek knowledge using traditional method. Hence, because of minimum prior experience with technology for knowledge exchange, teachers might consider virtual teaching untrustworthy.

2523-6547 - Copyright: (C) 2017 The Authors. This is an open access article distributed under the terms of the Creative Commons Attribution License, which permits unrestricted use, distribution, and reproduction in any medium, provided the original author and source are credited. 
Results of both the studies suggested a positive and significant relationship between "social influence (SI) and trust". These findings are similar to past studies, where researchers examined the increase in the level of trust due to preference led by the familiar people. In reality, individuals accept/reject to perform an action on the basis of the recommendations from the known ones. These preferences led by others, help an individual to build "trust". Although people rely more on their in-groups', but studies suggested that trust also exist with in dissimilar group. This trust on out-group's can be due to their similar beliefs and intentions. But to develop trust on a technology, there is a need to have positive word of mouth and feedback from the familiar and dissimilar groups. Henceforth in the current study, as the users are switched from traditional teaching/learning method to virtual teaching/learning environment, therefore to build trust on ICT, there is a need to have a positive feedback and influence from the referent groups.

The results illustrated a positive and significant effect of "facilitating condition" (FC) on "trust" with coefficient path reported for study $1(0.178, \mathrm{p}<0.001)$ and study $2(0.240, \mathrm{p}<0.005)$ respectively. Facilitating conditions are the support and guidance ("technical and non-technical") that are rendered to the users of technology by the organization/institute. It is believed that user's willingness to use a technology (along with other factors) is based on how much he/she trusts the technology. And to make a technology trustworthy, researchers suggested that organizations should provide support, guidance and training to the users (Lu et al., 2005). Nowadays, live chat 24/7, video clips, FAQ and images are uploaded on the company's website for guiding the users; that eventually helps in building user trust on system/technology.

Keeping in view the current study, full support and guidance is provided to the users who use ICT for knowledge exchange. In reality, teachers can perform their knowledge sharing activities during their office hours. Hence, full technical and non-technical support is rendered to them by the institute. Moreover even for students, help manuals are available on the website; plus users can send emails to support staffs about the issue, who are bound to respond within 24 working hours. These activities help in building user trust on ICT for knowledge exchange.

Trust has a positive and significant influence on user behavioral intention to use ICT for knowledge sharing and seeking.

There are many factors that affect user behavior, but trust is considered as the main element (Gefen et al., 2003). Fortunately, results reported significant effect of trust on "intention" (INT), and these findings are aligned with the past researches ( e.g. McKnight et al., 2002; Gefen et al., 2003), where research frameworks were formulated to test the role of trust in developing a relationship between the two parties (individuals or organization) or between user and technology (McKnight et al., 2002; Gefen et al., 2003; Ribbink et al., 2004; Grabner-Krauter $\&$ Kaluscha, 2008); that eventually helps in developing user's willingness to perform a behavior (e.g. Mcknight et al., 2002; Gefen et al., 2003) or for making any “exchange relationships” successful (Kim, Ferrin \& Rao, 2008).

2523-6547 - Copyright: (C) 2017 The Authors. This is an open access article distributed under the terms of the Creative Commons Attribution License, which permits unrestricted use, distribution, and reproduction in any medium, provided the original author and source are credited. 
In a virtual teaching/learning environment, where knowledge exchanged between the student and teacher is mediated through ICT, trust on ICT is an essential element (Wang, 2014). It helps in reducing the risks and ambiguities in the mind of the individuals and possesses a positive behavior towards its usage. Like: student using ICT for knowledge seeking might consider it difficult to use, and on the basis of perceived risk associated in their minds, distrust the technology and fails to use it. Similarly researchers have reported the importance of technology-based trust in making teachers use ICT for knowledge sharing (Allen \& Seaman, 2013).

Table 5: Hypotheses testing results

\begin{tabular}{|c|c|c|c|}
\hline Hypotheses & Structural path & Coefficient & Testing result \\
\hline H1a (study 1) & \multirow{2}{*}{ Performance expectancy $\rightarrow$ Trust } & $0.155,(\mathrm{p}<0.05)$ & \multirow{3}{*}{ Accepted } \\
\hline H1b (study 2) & & $0.216,(\mathrm{p}<0.05)$ & \\
\hline H2a (study 1 ) & \multirow{2}{*}{ Effort expectancy $\rightarrow$ Trust } & $0.214,(\mathrm{p}<0.05)$ & \\
\hline H2b (study 2) & & $n s$ & Rejected \\
\hline H3a (study 1) & \multirow{2}{*}{ Social influence $\rightarrow$ Trust } & $0.197,(\mathrm{p}<0.05)$ & \multirow{6}{*}{ Accepted } \\
\hline H3b (study 2) & & $0.173,(\mathrm{p}<0.05)$ & \\
\hline H4a (study 1 ) & \multirow{2}{*}{ Facilitating condition $\rightarrow$ Trust } & $0.178,(\mathrm{p}<0.05)$ & \\
\hline $\mathrm{H} 4 \mathrm{~b}$ (study 2) & & $0.240,(\mathrm{p}<0.05)$ & \\
\hline H5a (study 1) & \multirow{2}{*}{ Trust $\rightarrow$ Behavioral Intention } & $0.620,(\mathrm{p}<0.05)$ & \\
\hline H5b (study 2) & & $0.546,(\mathrm{p}<0.05)$ & \\
\hline
\end{tabular}




\section{Limitations and Future Directions}

Although rigorous research measures and procedures were followed and used, this study still has some limitations that should be addressed in future researches. Firstly: in general, with the formulation or extension of a theory, the potential limitation reported by the researchers is the "generalizability of the findings". Generalizability is referred as "the validity of a theory in a setting different from the one where it was empirically tested and confirmed". Hence, to test the generalizability of the findings revealed in the current study, there is a need to test the model in other context of online exchanges like: online shopping, online banking etc.

Secondly: in the current study, an extended version of UTAUT was developed based on the gap and need identified in the literature. For this data was collected from 150 teachers of 2 public sector universities. This sample size of 150 is one of the potential limitations for the current research, because researchers and methodologists in past have suggested a recommended sample size for conducting the research, like: ten times the number of items (Velicer \& Fava, 1998) or minimum 200 sample size (Meyer et al., 2012). But because of small population, the current study failed to engage more number of respondents to participate. It has been reported that insufficient sample size causes in failure to achieve required results and reduces "the power of significant tests" (Meyers et al., 2012). Therefore in future, study should be conducted to evaluate teachers ICT usage behavior for knowledge sharing with reasonable number of sample size.

Thirdly: the construct, trust was measured using scale developed by Cho and Fiorito (2009). As it was developed for testing user trust in online shopping, therefore, for the current research, the scale was adapted keeping in view the context of the study i.e. e-learning. According to Wang (2014) and upto authors knowledge, no quantitative study has been conducted that tested user trust on e-learning. Therefore, the current research used a single construct to measure user trust. No doubt the instrument depicted strong psychometric properties by scientifically proving it to be reliable and valid. But in future, a scale particularly to tap user trust on ICT / e-learning is needed to be developed, that would help researchers in testing user trust in e-learning. In addition, based on the dimensions (i.e. reliability, helpfulness and functionality) suggested by McKnight et al., (2011); in future, studies should be conducted to get an in depth understanding that which trust dimension actually leads to user technology acceptance behavior.

\section{Conclusion}

In reality, universities are increasing so is the competition, and to overcome this issue universities are investing on ICT to grab students situated at far away location. Hence they are transforming from traditional education system to online learning. They have invested their time and cost towards the implementation of ICT but failed to make it successful. So the findings suggested in the current research elaborates the factors responsible for building user trust on ICT and making the actual use of system successful at both teacher and student side for knowledge exchange.

Both the studies use performance expectancy, effort expectancy, social influence, and facilitating condition as determinants to user trust that eventually influences user behavioral intention. Some of the findings of the both the studies reported results other than proposed, like: insignificant relationship between effort expectancy (EE) and trust in study 2. Moreover, lack of literature exists on the role of trust in virtual leaning environment. Although extensive studies on online trust has been conducted in e-commerce, but trust in align with the e-learning and especially in Pakistan is hardly been studied.

To conclude, this study contributes to the existing body of knowledge by (a) testing factors affecting teachers and students' technology acceptance behavior for knowledge sharing and seeking separately, (b) extending the UTAUT developed by Venkatesh et al., (2003), and incorporating trust as an "explanatory factor" that helps in examining users perceive insecurity about the ICT in use. In addition, the relationship suggested in this study provides considerable implications for designers, IT support managers and top management of the universities. Like: the theoretical framework can be used: (a) as a "designing tool" by the designers, to investigate which construct fails to explain users ICT acceptance for KE; and (b) by the top-management to identify where investment is needed to be made i.e. whether IT managers should be asked to develop ICT more easier, useful with more technical supports, or IT support office should be asked to perform accordingly as needed.

2523-6547 - Copyright: (C) 2017 The Authors. This is an open access article distributed under the terms of the Creative Commons Attribution License, which permits unrestricted use, distribution, and reproduction in any medium, provided the original author and source are credited. 
2523-6547 - Copyright: (C) 2017 The Authors. This is an open access article distributed under the terms of the Creative Commons Attribution License, which permits unrestricted use, distribution, and reproduction in any medium, provided the original author and source are credited. 


\section{References}

Allen, I. E., \& Seaman, J. (2013). Changing Course: Ten Years of Tracking Online Education in the United States. Sloan Consortium.

Azizi, S. (2014). A Model of Factors Affecting Foreign Brand Trust. Journal of Competitiveness. 6(3), $20-31$.

Ba, S., \& Pavlou, P. A. (2002). Evidence of the effect of trust building technology in electronic markets: Price premiums and buyer behavior. MIS Quarterly, 26(3), 243-268. doi: 10.2307/4132332.

Blau, P. M. (1964). Exchange and power in social life. Transaction Publishers.

Bock, G-W., Kankanhalli, A., \& Sharma, S. (2006). Are norms enough? The role of collaborative norms in promoting organizational knowledge seeking. European Journal of Information Systems, 15(4), 357-367. doi:10.1057/palgrave.ejis.3000630.

Brengman, M., \& Karimov, F. P. (2012). The effect of web communities on consumers' initial trust in B2C ecommerce websites. Management Research Review, 35(9), 791-817. Doi: $10.1108 / 01409171211256569$.

Byrne, B. M. (2010). Structural Equation Modeling with AMOS: Basic Concepts, Applications and Programming. New York: Routledge.

Castelfranchi, C. \& Falcone, R. (1998). Social Trust: cognitive anatomy, social importance, quantification and dynamics. Proceedings of the First International Workshop on Deception, Fraud and Trust in Agent Societies, 35-49.

Chen, C, J., \& Hung, S, W. (2010). To give or to receive? Factors influencing members' knowledge sharing and community promotion in professional virtual communities. Information \& Management, 47(4), 226-236. doi:10.1016/j.im.2010.03.001.

Chinomona, R. (2013). The influence of perceived ease of use and perceived usefulness on trust and intention to use mobile social software: technology and innovation. African Journal for Physical Health Education, Recreation and Dance, 19(2), 258-273.

Cho, H., \& Fiorito, S. S. (2009). Acceptance of online customization for apparel shopping, International Journal of Retail \& Distribution Management, 37(5), 389-407. doi: 10.1108/09590550910954892

Coakes, S. J., \& Steed, L. G. (2003). SPSS analysis without anguish. Sydney: John Wiley \& Sons.

Corritore, C. L., Kracher, B., \& Wiedenbeck, S. (2003). On-line trust: concepts, evolving themes, a model. International Journal of Human-Computer Studies, 58(6), 737-758. doi: 10.1016/S10715819(03)00041-7

Cox, T. (1994). Cultural diversity in organizations: Theory, research and practice. San-Francisco: BerrettKoehler Publishers.

Curran, P. J., West, S. G., \& Finch, J. F. (1996). The robustness of test statistics to nonnormality and specification error in confirmatory factor analysis. Psychological Methods. 1(1), 16-29. doi: 10.1037/1082989X.1.1.16

Davis, F. D., Bagozzi, R. P., \& Warshaw, P. R. (1989). User acceptance of computer technology: a comparison of two theoretical models. Management Science, 35(8), 982-1003. doi: 10.1287/mnsc.35.8.982

Fishbein, M., \& Ajzen, I. (1975) Belief, Attitude, Intention and Behavior: An Introduction to Theory and Research, Addison-Wesley publishing

Gefen, D., \& Straub, D. W. (2003). Managing user trust in B2C e-services. E-service Journal, 2(2), 7-24.

Gefen, D., Karahanna, E., \& Straub, D. W. (2003). Trust and TAM in Online Shopping: An Integrated Model. MIS Quarterly, 27(1), 51-90.

Ghadirian, H., Ayub, A. F. M., Silong, A. D., Bakar, K. B. A., \& Zadeh, A. M. H. (2014). Knowledge sharing behaviour among students in learning environments: A review of literature. Asian Social Science, 10(4), 38-45. doi: $10.5539 /$ ass.v10n4p38

Grabner-Kräuter, S., \& Kaluscha, E. A. (2003). Empirical research in on-line trust: a review and critical assessment. International Journal of Human-Computer Studies, 58(6), 783-812. doi:10.1016/S10715819(03)00043-0.

Grabner-Kräuter, S., \& Kaluscha, E. A. (2008) Consumer trust in electronic commerce: conceptualization and classification of trust building measures. In T. Kautonen \& H. Karjaluoto (Eds.), Trust and New Technologies: Marketing and Management on the Internet and Mobile Media (pp 3---22). Edward Elgar, Cheltenham.

Gray, P. H., \& Durcikova, A. (2005). The role of knowledge repositories in technical support environments: Speed versus learning in user performance. Journal of Management Information Systems, 22(3), 159-190.

2523-6547 - Copyright: (C) 2017 The Authors. This is an open access article distributed under the terms of the Creative Commons Attribution License, which permits unrestricted use, distribution, and reproduction in any medium, provided the original author and source are credited. 
Hair, J. F., Black, W. C., Babin, B. J., \& Anderson, R. E. (2010). Multivariate data analysis (7th ed.). New Jersey: Pearson Education, Inc.

Hart, P., \& Saunders, C. (1997). Power and trust: Critical factors in the adoption and use of electronic data interchange. Organization science, 8(1), 23-42. doi: 10.1287/orsc.8.1.23

He, W., \& Wei, K.K. (2009). What drives continued knowledge sharing? An investigation of knowledgecontribution and-seeking beliefs. Decision Support Systems, 46(4), 826-838. doi:10.1016/j.dss.2008.11.007.

He, W., Fang, Y., \& Wei, K. K. (2009). The role of trust in promoting organizational knowledge seeking using knowledge management systems: An empirical investigation. Journal of the American Society for Information Science and Technology, 60(3), 526-537. doi: 10.1002/asi.21006.

Hopgood, A. A., \& Hirst, A. J. (2007). Keeping a distance-education course current through eLearning and contextual assessment. IEEE Transactions on Education, 50(1), 85-96. doi: 10.1109/TE.2006.888905.

Hoyle, R. H. (2012). Handbook of structural equation modeling. New York, NY: Guilford Press.

Jarvenpaa, S. L., Shaw, T. R., \& Staples, D. S. (2004). Toward contextualized theories of trust: The role of trust in global virtual teams. Information systems research, 15(3), 250-267. doi: 10.1287/isre.1040.0028.

Jarvenpaa, S. L., Tractinsky, N., \& Saarinen, L. (1999). Consumer trust in an Internet store: a cross-cultural validation. Journal of Computer-Mediated Communication,5(2), 1-37. doi: 10.1111/j.10836101.1999.tb00337.x.

Kankanhalli, A., Lee, O. K. D., \& Lim, K. H. (2011). Knowledge reuse through electronic repositories: A study in the context of customer service support. Information \& Management, 48(2), 106-113. doi: 10.1016/j.im.2011.02.002.

Kankanhalli, A., Tan, B. C., \& Wei, K. K. (2005). Understanding seeking from electronic knowledge repositories: An empirical study. Journal of the American Society for Information Science and Technology, 56(11), 1156-1166. doi: 10.1002/asi.v56:11.

Karahanna, E., Straub, D. W., \& Chervany, N. L. (1999). Information technology adoption across time: a crosssectional comparison of pre-adoption and post-adoption beliefs. MIS Quarterly, 23(2), 183-213. doi: 10.2307/249751.

Karimov, F. P., Brengman, M., Van-Hove, L., \& Van, L. (2011). The effect of website design dimensions on initial trust: a synthesis of the empirical literature. Journal of Electronic Commerce Research, 12(4), 272-301.

Kelly, J., \& Kelly, C. (1991). Them and Us': Social Psychology and 'The New Industrial Relations. British Journal of Industrial Relations, 29(1), 25-48. doi: 10.1111/j.1467-8543.1991.tb00226.x.

Kelman, H. C. (1958). Compliance, identification, and internalization: Three processes of attitude change. Journal of conflict resolution, 2(1), 51-60.

Kenny, D.A. (2014). Mediation. Retrieved from http://davidakenny.net/cm/mediate.htm

Kim, D. J., Ferrin, D. L., \& Rao, H. R. (2008). A trust-based consumer decision-making model in electronic commerce: The role of trust, perceived risk, and their antecedents. Decision Support Systems, 44(2), 544564. doi:10.1016/j.dss.2007.07.001.

Kini, A., \& Choobineh, J. (1998, January). Trust in electronic commerce: definition and theoretical considerations. Proceedings of the Thirty-First Hawaii International Conference on System Sciences, 4, 51-61. doi: 10.1109/HICSS.1998.655251

Kline, R. B. (2011). Principles and practice of structural equation modeling (3rd ed.). New York, Guilford Press

Korb, K. A.(2012). Conducting Educational Research: Adopting and adapting an instrument, Retrieved from: http://korbedpsych.com/R09aAdopt.html

Kumar, N. (1996). The power of trust in manufacturer-retailer relationships. Harvard business review, 74(6), 92106.

Lai, H. M., Chen, C.P., \& Chang, Y.F. (2014). Determinants of knowledge seeking in professional virtual communities. Behaviour \& Information Technology, 33(5), 522-535. doi: 10.1080/0144929X.2013.864709.

Li, F., Pienkowski, D., Moorsel, A. V., \& Smith, C. (2012). A Holistic Framework for trust in Online Transactions, International Journal of Management Reviews, 14(1), 85-103. doi: 10.1111/j.1468-2370.2011.00311.x.

Lin, T. C., \& Huang, C. C. (2008). Understanding knowledge management system usage antecedents: An integration of social cognitive theory and task technology fit. Information \& Management, 45(6), 410417. doi:10.1016/j.im.2008.06.004.

Lu, J., Yu, C., \& Liu, C. (2005). Facilitating conditions, wireless trust and adoption intention. Journal of Computer Information Systems, 46(1), 17-24.

2523-6547 - Copyright: (C) 2017 The Authors. This is an open access article distributed under the terms of the Creative Commons Attribution License, which permits unrestricted use, distribution, and reproduction in any medium, provided the original author and source are credited. 
Mac-Callum, K., \& Jeffrey, L. (2013). The influence of students' ICT skills and their adoption of mobile learning. Australasian Journal of Educational Technology, 29(3), 303-314. doi: 10.1234/ajet.v29i3.298.

MacKinnon, J. (2006). Bootstrap methods in econometrics. (No. 1028). Retrieved from Queens Economics Department Working paper website: http://qed.econ.queensu.ca/working_papers/papers/qed_wp_1028.pdf

McKnight, D. H., \& Chervany, N. L. (2002). What Trust Means in E-Commerce Customer Relationships: An Interdisciplinary Conceptual Typology. International Journal of Electronic Commerce, 6(2), 35-59.

Mcknight, D. H., Carter, M., Thatcher, J. B., \& Clay, P. F. (2011). Trust in a specific technology: An investigation of its components and measures. ACM Transactions on Management Information Systems, 2(2), 12-32. doi: $\underline{10.1145 / 1985347.1985353}$

McKnight, D. H., Choudhury, V., \& Kacmar, C. (2002). The impact of initial consumer trust on intentions to transact with a web site: a trust building model. Journal of Strategic Information Systems, 11(3), 297323. doi: 10.1016/S0963-8687(02)00020-3

McKnight, D. H., Cummings, L. L., \& Chervany, N. L. (1998). Initial trust formation in new organizational relationships. Academy of Management review, 23(3), 473-490.

Meyers, L. S., Gamst, G., \& Guarino, A. J. (2012). Applied multivariate research: Design and interpretation. Thousand Oaks: Sage Publications.

Meyerson, D., Weick, K. E., \& Kramer, R. M. (1996). Swift trust and temporary groups. In R. M. Kramer \& T. R. Tyler (Eds.), Trust in organizations: Frontiers of theory and research (pp. 166-195). Thousand Oaks, CA: Sage.

Norman, G. (2010). Likert scales, levels of measurement and the "laws"'of statistics, Advances in Health Sciences Education, 15(5), 625-632. doi: 10.1007/s10459-010-9222-y.

Olson, J. C., \& Jacoby, J. (1972). Cue utilization in the quality perception process. Proceedings of the $2^{\text {nd }}$ Annual Convention of the Association for Consumer Research, 2, 167-179.

Oye, N. D., Salleh, M., \& Iahad, N. A. (2011). Challenges of E-learning in Nigerian University Education Based on the Experience of Developed Countries. International Journal of Managing Information Technology, $3(2), 39-48$.

Pavlou, P. A. (2003). Consumer acceptance of electronic commerce: Integrating trust and risk with the technology acceptance model. International journal of electronic commerce, 7(3), 101-134.

Pavlou, P. A., Tan, Y. H., \& Gefen, D. (2003, June). Institutional trust and familiarity in online interorganizational relationships. Proceedings of the European Conference on Information Systems, Italy. Retrieved from http://papers.ssrn.com/sol3/papers.cfm?abstract_id=2380660

Phang, C. W., Kankanhalli, A., \& Sabherwal, R. (2009). Usability and sociability in online communities: A comparative study of knowledge seeking and contribution. Journal of the Association for Information Systems, 10(10), 721-747.

Qiu, L., \& Benbasat, I. (2005). Online consumer trust and live help interfaces: The effects of text-to-speech voice and three-dimensional avatars. International Journal of Human-Computer Interaction, 19(1), 75-94. doi: 10.1207/s15327590ijhc1901_6.

Reichheld, F. F., \& Schefter, P. (2000). E-loyalty: Your secret weapon on the web. Harvard Business Review, 78(4), 105-113.

Ribbink, D., Van Riel, A. C., Liljander, V., \& Streukens, S. (2004). Comfort your online customer: quality, trust and loyalty on the Internet. Managing Service Quality: An International Journal, 14(6), 446-456. doi: $\underline{10.1108 / 09604520410569784}$

Sekaran, U. (2003). Research Methods for Business: A Skill-Building Approach. United States of America: John Wiley \&Sons, Inc.

Stevens, J. (2002). Applied Multivariate Statistics for the Social Sciences (4th Edition). Mahwah, NJ: Lawrence Erlbaum Associates.

Suh, B., \& Han, I. (2002). Effect of trust on customer acceptance of Internet banking. Electronic Commerce research and applications, 1(3), 247-263. doi:10.1016/S1567-4223(02)00017-0.

Sumak, B., HeričKo, M., \& PušNik, M. (2011). A meta-analysis of e-learning technology acceptance: The role of user types and e-learning technology types. Computers in Human Behavior, 27(6), 2067-2077. doi:10.1016/j.chb.2011.08.005

Tabachnick, B. G., \& Fidell, L. S. (2007). Using multivariate statistics (5th ed.). Boston, MA: Allyn and Bacon.

Tan, Y. H., \& Thoen, W. (2000). Toward a generic model of trust for electronic commerce. International Journal of Electronic Commerce, 5(2), 61-74.

Taylor, S., \& Todd, P. (1995 a). Understanding information technology usage: A test of competing models. Information systems research, 6(2), 144-176. doi: 10.1287/isre.6.2.144

2523-6547 - Copyright: (C) 2017 The Authors. This is an open access article distributed under the terms of the Creative Commons Attribution License, which permits unrestricted use, distribution, and reproduction in any medium, provided the original author and source are credited. 
Taylor, S., \& Todd, P. (1995 b). Assessing IT usage: The role of prior experience. MIS Quarterly, 19(4), 561-570. doi: $10.2307 / 249633$.

Ullman, J. B. (2006). Structural equation modeling: Reviewing the basics and moving forward. Journal of Personality Assessment, 87(1), 35-50.

Velicer, W. F., \& Fava, J. L. (1998). Effects of variable and subject sampling on factor pattern recovery. Psychological Methods, 3, 231-251.

Venkatesh, V., Morris, M. G., Davis, G. B., \& Davis, F. D. (2003). User acceptance of information technology: Toward a unified view. MIS Quarterly, 27(3), 425-478.

Venkatesh, V., Thong, J. Y., \& Xu, X. (2012). Consumer acceptance and use of information technology: extending the unified theory of acceptance and use of technology. MIS Quarterly, 36(1), 157-178.

Wang, D. (2014). Building Trust in E-learning. Athens Journal of Education, 1(1), 9-18.

Wang, S., \& Noe, R. A. (2010). Knowledge sharing: A review and directions for future research. Human Resource Management Review, 20(2), 115-131. doi:10.1016/j.hrmr.2009.10.001

Wang, W. \& Benbasat, I. (2005). Trust in and adoption of online recommendation agents. Journal of the Association for Information Systems, 6(3), 72-101.

Watson, S., \& Hewett, K. (2006). A Multi-Theoretical Model of Knowledge Transfer in Organizations: Determinants of Knowledge Contribution and Knowledge Reuse. Journal of Management Studies, 43(2), 141-173. doi: 10.1111/j.1467-6486.2006.00586.x.

Williams, M. (2001). In whom we trust: Group membership as an affective context for trust development. Academy of Management Review, 26(3), 377-396.

Williams, M. D., Rana, N. P., \& Dwivedi, Y. K. (2012). A Bibliometric Analysis of Articles Citing the Unified Theory of Acceptance and Use of Technology. In Y. K. Dwivedi, M. R. Wade \& S. L. Schneberger (Eds.) Information Systems Theory: Explaining and Predicting Our Digital Society: Vol. 1, Springer Science \& Business Media (pp. 37- 62). Retrieved from

http://link.springer.com/chapter/10.1007\%2F978-1-4419-6108-2_3

2523-6547 - Copyright: (C) 2017 The Authors. This is an open access article distributed under the terms of the Creative Commons Attribution License, which permits unrestricted use, distribution, and reproduction in any medium, provided the original author and source are credited. 
2523-6547 - Copyright: (C) 2017 The Authors. This is an open access article distributed under the terms of the Creative Commons Attribution License, which permits unrestricted use, distribution, and reproduction in any medium, provided the original author and source are credited. 